\title{
A presença do movimento acrobático nas manifestações culturais dançadas
}

\author{
La presencia del movimiento acrobático en el baile de manifestaciones \\ culturales
}

The presence of the acrobatic movement in cultural danced manifestations

\author{
Guilherme Conrad ${ }^{1}$
}

\begin{abstract}
Resumo
O presente artigo realiza uma análise histórico-cultural da presença do movimento acrobático nas manifestações culturais dançadas. Movendo-se por diferentes culturas e estilos, a pesquisa estabelece as variadas relações da técnica acrobática com o corpo que dança. A análise perpassa pelos rituais de caça primitivos, danças antigas egípcias, gregas, cretenses, romanas, feudais, dança extática balinesa sang hyang dedari, dança das armas do imperador chinês Huang Ti, dança clássica, music hall, dança-teatro, contato-improvisação, dança vertical, bailes de salão, rock'n'roll acrobático, danças folclóricas, hip-hop, capoeira e teatro musical. O estudo, embasado através de perspectivas históricas e antropológicas associadas a conceitos da Antropologia Teatral do diretor italiano Eugenio Barba (1936-), das técnicas do corpo do antropólogo francês Marcel Mauss (1872-1950) e da Etnocenologia, pressupõe como a Acrobacia é presente em performances artísticas e culturais que, ao colocar o homem em um contexto imaginário por meio de rupturas perceptivas e corporais que desafiam as leis gravitacionais conjuntamente com uma expansão de qualidades físicas e motoras. Através dos exemplos dissertados, o artigo conclui como a partir da relação entre o artístico e o cultural o movimento acrobático desponta com base em inúmeros fatores de cunho cultural, social, ritual, religioso, festivo, espetacular, técnico, virtuoso, expressivo, pedagógico, lúdico, coreográfico ou de treinamento.
\end{abstract}

Palavras-chave: Acrobacia; Dança; Técnicas corporais; Antropologia Teatral; Etnocenologia.

\section{Resumen}

Este artículo presenta un análisis histórico-cultural de la presencia del movimiento acrobático en manifestaciones culturales bailadas. Moviéndose a través de diferentes culturas y estilos, la investigación establece las variadas relaciones de la técnica acrobática con el cuerpo danzante. El análisis impregna rituales de caza primitivos, danzas antiguas egipcias, griegas, cretenses, romanas, feudales, danza extática balinesa sang hyang dedari, danza de los brazos del emperador chino Huang Ti, danza clásica, salón de música, teatro de baile, improvisación de contacto, baile vertical, salones de baile, rock'n'roll acrobático, bailes folclóricos, hip hop, capoeira y teatro musical. El estudio, basado en perspectivas históricas y antropológicas asociadas con los conceptos de la Antropología Teatral del director italiano Eugenio Barba (1936-), las técnicas del cuerpo del antropólogo francés Marcel Mauss (1872-1950) y la Etnocenología, presupone cómo la acrobacia está presente en representaciones artísticas y culturales que, al colocar al hombre en un contexto imaginario a través de interrupciones perceptivas y corporales que desafían las leyes gravitacionales junto con una expansión de las cualidades físicas y motoras. A través de los ejemplos disertados, el artículo concluye que de la relación entre lo artístico y lo cultural, el movimiento acrobático emerge en base a numerosos factores culturales, sociales, rituales, religiosos, festivos, espectaculares, técnicos, virtuosos, expresivos, pedagógicos, juguetón, coreográfico o de entrenamiento.

Palabras claves: Acrobacia; Danza; Técnicas corporales; Antropología teatral; Etnocenología.

\footnotetext{
Abstract

${ }^{1}$ Doutorando em Artes Cênicas; Programa de Pós-graduação em Artes Cênicas da Universidade Federal do Rio Grande do Sul; Porto Alegre, Rio Grande do Sul, Brasil; guilhermeconra@gmail.com.
} 
This article presents a historical and cultural analysis of the presence of acrobatic movement in danced cultural manifestations. Moving through different cultures and styles, it establishes the varied relationships of the acrobatic technique with the dancing body. Analysis runs through primitive hunting rituals, ancient Egyptian, Greek, Cretan, Roman and feudal dances, Balinese ecstatic dance sang hyang dedari, dance of the arms of the Chinese emperor Huang Ti, classical dance, music hall, dance-theater, contact-improvisation, vertical dance, ballrooms, acrobatic rock'n'roll, folk dances, hip hop, capoeira and musical theater. The study, based on historical and anthropological perspectives in conjunction with concepts of Theatre Anthropology of Italian director Eugenio Barba (1936-), the body techniques of the French anthropologist Marcel Mauss (1872-1950) and Ethnocenology, presupposes how acrobatics is present in artistic and cultural performances that, by placing the man in an imaginary context through perceptual and bodily disruptions that defy gravitational laws in conjunction with an expansion of physical and motor qualities. Through the dissertated examples, the article concludes that from the relationship between the artistic and the cultural, the acrobatic movement emerges based on numerous factors of cultural, social, ritual, religious, festive, spectacular, technical, virtuous, expressive, pedagogical, playful, choreographic or training expression.

Key words: Acrobatics; Dance; Body techniques; Theatre Anthropology; Etnocenology.

\section{Introdução}

As acrobacias são movimentos cuja execução exige grande habilidade de destrezas físicas como força, agilidade, flexibilidade, equilíbrio e que, ao expandir os limites corporais, colocam o corpo em exposição ao risco, em relação inabitual com as leis da gravidade e em configuração extracotidiana. De forma geral, são associadas quase que imediatamente ao esporte (como elementos que compõem o repertório de ginastas olímpicos) ou ao circo (como artimanhas feitas por artistas em diferentes modalidades). Entretanto, além da institucionalização destes espaços e suas finalidades virtuosas, há registros de execução da posição acrobática da "ponte" por bailarinas pelo menos desde o Egito Antigo, enquanto que inversões apoiadas pelos braços também são populares em rodas de capoeira. Desta forma, quais são os propósitos que faz o movimento acrobático estar presente em manifestações culturais que se expressam através da dança? Através da perspectiva das técnicas do corpo de Marcel Mauss, da Antropologia Teatral de Eugenio Barba e da Etnocenologia de Jean-Marie Pradier, o artigo perpassa por diferentes territórios e estilos de dança através de uma via temporal para identificar os movimentos acrobáticos e suas funções em manifestações culturais dançadas.

\section{Rituais antigos}

Através de figuras, lendas e relatos antigos, é possível perceber a presença de movimentos acrobáticos em diferentes civilizações primitivas, na medida em que o domínio da natureza, do seu entorno, do outro e por fim, do próprio corpo, se mostravam cada vez mais necessários para os processos evolutivos. A busca pela sobrevivência dos caçadores exigia o controle de habilidades enraizadas em atividades cotidianas onde destrezas físicas como a força, a velocidade, agilidade, equilíbrio e flexibilidade eram imprescindíveis para a 
alimentação, ataque e defesa, assemelhando-se à configuração de uma corporalidade animal. A intenção de um grande comando e eficácia dos movimentos hominídeos para o aproveitamento em seu favor possibilitou, portanto, o princípio de manifestações corporais acrobáticas.

Os rituais de caça que remontam à Era do Gelo estão ligados ao surgimento das artes da cena, em que a figura de um ator representava o animal a ser caçado, que, conjuntamente com danças e músicas, tinha o propósito de estimular bons presságios. O domínio de capacidades corporais acrobáticas também remete à cena ritual $^{2}$, em que os movimentos de rotação e inversão constituíam a base de um simbolismo circular, em que o corpo invertido e giros dos acrobatas estabeleciam um ponto de conexão e comunicação com o divino (ROHE, 2014, p. 85). A mobilidade acrobática de curvaturas se convertia em ato religioso e em gestos de adoração, associando-se ao sagrado, às figuras celestes ou ao fato de implicar uma habilidade sobre-humana (MENIL, 1905, p. 125), identificando o ser humano com os deuses e fazia com que estes se manifestassem através de seus corpos.

\section{Sang Hyang Dedari}

A associação da incorporação de divindades através de movimentos acrobáticos é vista na dança das bailarinas balinesas sang hyang dedari. Entidades espirituais importantes na antiga mitologia indonésia como Tunjung Biru e Supraba são invocados nesta dança sagrada executada exclusivamente em cerimônias religiosas hindus em Bali como uma forma de veneração por uma colheita abundante e saudável, de reparação social e proteção da comunidade. O processo catártico é realizado em um estado de possessão (kerawuhan) induzido por incensos e mantras cantados (gending). Jovens meninas de 7 a 12 anos, consideradas puras, executam na dinâmica da dança figuras acrobáticas como posições arqueadas e são expostas ao risco físico.

Quando a cerimônia acontece e todas as preparações religiosas são seguidas, o corpo humano mortal, antes um corpo profano longe da perfeição e sujeito às necessidades e falhas humanas básicas, passa a não mais a pertencer às suas limitações humanas, sendo reverenciados como corpos sagrados, capazes de realizar obras extraordinárias, impermeáveis ao perigo e outras fraquezas humanas: "sendo a personificação das deusas (Dedari), elas agem alegremente; dançando, tocando e até realizando atos perigosos, como caminhar pelo

\footnotetext{
${ }^{2}$ Desta forma, esta associação entre os rituais de caça, o ator e acrobacia pode reiterar as teorias de Fu Qifeng, que considera o movimento acrobático como a primeira manifestação artística corporal do homem (1985).
} 
fogo, subir a bambus de 4 metros de altura sem medo e sem ferimentos" (PUTRI, 2017, p. 76).

Mesmo estando de olhos fechados, pode-se identificar, no corpo das bailarinas, um sincronismo nos movimentos e uma ausência de medo e hesitação na ação dos gestos. Estas características podem ser vistas como não habituais da essência humana, simbolizando, portanto, uma condição sobre-humana, a identificação e comunicação com o divino e natureza e a êxtase do corpo (CHEVALIER e GHEERBRANT, 1995, p. 47), mesmo que, após o término do ritual, as bailarinas não lembrem as ações que realizaram.

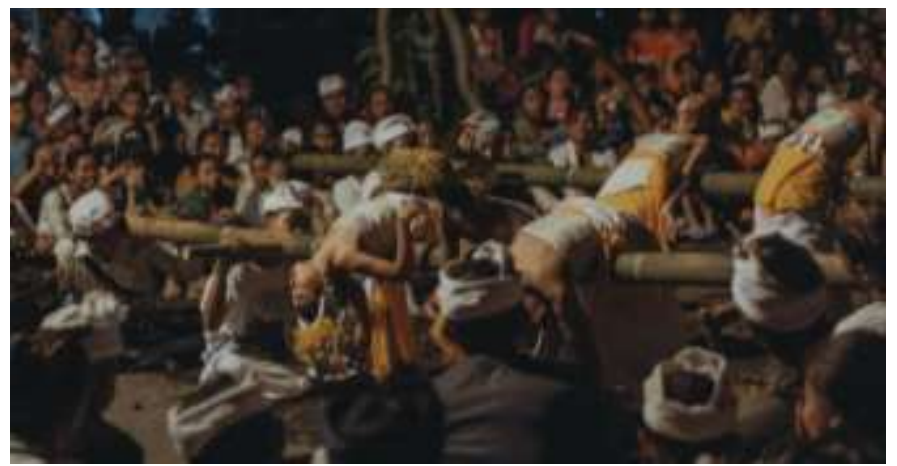

FiguraA 1 - Bailarinas balinesas em posições arqueadas. Disponível em: https://www.flickr.com/photos/ndravens/33582125408/. Acessado 17/12/19.

\section{Egito Antigo}

O simbolismo circular dos movimentos acrobáticos também constituía uma base das manifestações culturais dançadas no Antigo Egito, onde bailarinas acrobatas atuavam com saltos e giros em cerimônias de cultos divinos e funerários. Como figura fúnebre, o corpo invertido evocava o giro da morte (BROZAS, 2004, p. 13-14), formando as imagens encontradas em estelas, tumbas e papiros. Estas imagens representadas apresentam uma semelhança com exercícios da Ginástica atual, apesar de que as sequências acrobáticas eram intrinsecamente ligadas à dança, não sendo executadas de forma isolada (ROHE, op. cit., p. 116). A posição arqueada para trás, por exemplo, era uma postura de dança muito comum e lembra a posição da "ponte" dos esportes gímnicos.

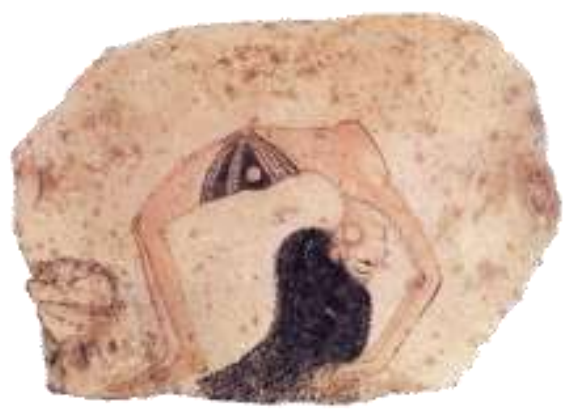


Figura 2 - Óstraco representando uma bailarina egípcia em posição acrobática, datando de cerca de 1292-1070 A.C. Disponível em: https://historiaprimeiroanoalasallesp.wordpress.com/2015/04/22/a-musica-o-canto-e-a-danca/.

Acessado em 18/12/2019.

Desde que, no Egito Antigo, ser uma bailarina já era uma profissão, muitas escolhiam realizar movimentos difíceis e vigorosos que exigiam muita flexibilidade e treinamento, não sendo todos possíveis de executar (LEXOVÁ, 2000, p. 22). Em uma descrição dos movimentos de dança das bailarinas egípcias, podemos identificar a natureza acrobática com uma execução de uma ponte em duplas:

Duas meninas de aproximadamente mesma altura e força adotam uma posição uma atrás da outra com as pernas abertas. A primeira arqueia o corpo quase na ponte e abraça a parceira na cintura, a outra garota se inclina seu corpo e agarra a primeira também em torno de sua cintura. Então a segunda levanta a primeira que está de cabeça para baixo e passa as pernas para ambos os lados da cabeça da parceira flexionando-as. A segunda garota se arqueia para fazer uma extensão tal que os pés da primeira tocam o chão e novamente a posição inicial é adotada, de maneira que os lugares e posições de ambas as meninas são trocados. Com treinamento suficiente elas podiam alcançar um domínio de tal forma que podiam executar uma série completa de cada movimento em um ritmo exato. (Ibidem, p. 23-24)

As danças acrobáticas aparecem em um contexto social de celebração de festividades reais, religiosas e privadas, onde "os saltos repetidos deviam ir se acentuando e acelerando-se (...) com o objetivo de destruir momentaneamente a individualidade e produzir um estado de exaltação extática permitindo que a divindade incorporasse nele" (CHEVALIER e GHEERBRANT, op. cit., p. 47). Em um relato de um jovem de Siracusa que, no século IV a.C fora convidado em Memphis por um rico egípcio para um banquete, descreve as danças com as quais o anfitrião entretinha seus convidados:

De repente, desapareceram e tomaram seu lugar no primeiro plano um grupo de dançarinos que saltou em todas as direções para voltar a se juntar e pular em cima um do outro com destreza incrível, montando em seus ombros e na cabeça, formando pirâmides, que atingiam o teto da sala, então eles desciam rapidamente um atrás de outro executando novos e admiráveis saltos mortais. (LEXOVÁ, op. cit., p. 23).

\section{Creta}

A função do movimento acrobático também desempenhava um papel importante na civilização pré-helênica de Creta nos ritos funerários, agrários, de fertilidade e fecundidade. Porém, a iconografia cretense vincula mais representativamente o movimento acrobático aos emblemas de espadas, vistas como sagradas e protetoras e atuantes em uma dança de espadas (AQUESOLO, 1992, p. 255). Em uma arma descoberta em 1936, há uma ênfase na figura que adorna o anel de ouro da parte inferior do punho: um acrobata arqueado que descreve um círculo completo com a cabeça tocando os pés, em mais um registro de simbologia circular. 


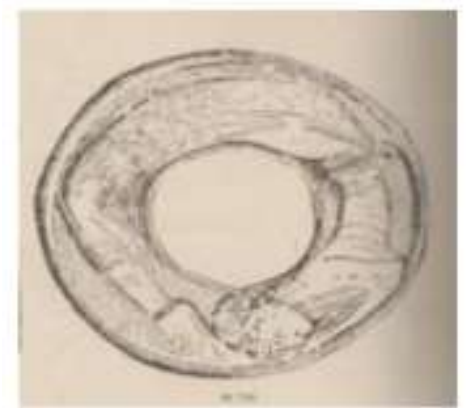

Figura 3. Acrobata em um aro de espada cretense. Fonte: DEONNA, 1953, p. 41.

Esta posição arqueada era também realizada sobre as costas de um touro nas touradas características de Creta. Os saltos, inversões, giros sobre o animal evocavam uma luta simbólica contra a morte e o destino, cujo caráter de risco típico do movimento acrobático se mostrava espetacular:

Os acrobatas pousavam suas mãos nas costas do animal e, aproveitando o impulso do salto, davam com uma cambalhota por cima das costas do animal e recuperam e recuperavam-se em pé atrás do touro. A execução desta manobra acrobática, que tinha que ser feito com a elegância exigida pelos cânones, exigia uma enorme coragem, e para acertar, emocionava profundamente os espectadores. Os cretenses estavam inclinados para o espetáculo coreográfico e arriscado de suas touradas acrobáticas, era um aspecto essencial do rito que poderia ser revestido um significado oracular. (MANDELL, 1986, p. 29-30).

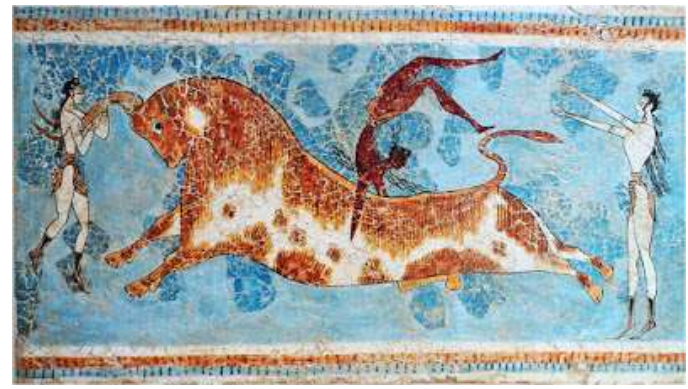

Figura 4. Pintura de um salto sobre o touro de aproximadamente 1500 A.C. Fonte:

https://www.auladehistoria.org/2016/02/fresco-salto-del-toro-o-taurocatapsia.html. Acessado em 18/12/19.

\section{Grécia Antiga e Império Romano}

Na sociedade grega, os movimentos acrobáticos aparecem conjuntamente com os bailarinos nos santuários e nas cerimônias divinas de culto a Dioniso, deus das danças, do Teatro, do vinho e das festas (MENIL, op. cit., p. 329). As procissões dionisíacas encenavam danças invertidas em posições arqueadas ou curvadas, denominadas "kubísticas", e tinham um caráter orgiástico e extático (PEIGNIST, 2009, p. 31). Quando executadas nos banquetes, avivavam o calor da comunicação, onde bailarinas dançavam sobre as mãos ou deslocavam-se assim sobre pontas de espadas e executavam antipodismos com objetos, arcos e flechas ou jarros cheios de vinho (ROHE, 2015, p. 29). 

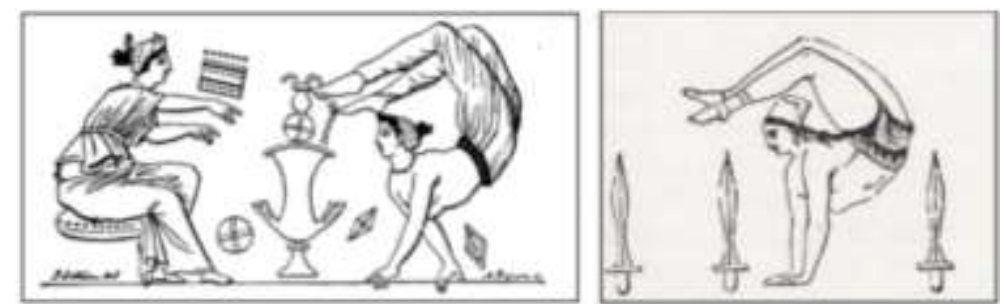

Figuras 5 e 6, respectivamente - bailarina carregando um jarro de vinho com os pés (DEPPING, 1871, p. 15) e exibição de dança invertida sobre espadas (STREHLY, 1977, p. 15).

No poema épico da Odisseia, há uma passagem explicitando o caráter festivo e de entretenimento das exibições acrobáticas, sempre ligadas à dança e à música: "Assim banqueteavam, na enorme casa de alto pé-direito, os vizinhos e camaradas do majestoso Menelau, com deleite. E entre eles cantava divino cantor com a lira; dois acrobatas, entre eles, liderando canto e dança, volteavam no meio (HOMERO, 2014, V, 15-19); assim como o soldado grego e discípulo de Sócrates, Xenofonte, relata a aprovação de Sócrates para com as danças, que incluíam piruetas acrobáticas por jovens bailarinas: "Então eles trouxeram um aro, com espadas colocadas ao seu redor, com a ponta para cima e a dançarina imediatamente saltou de cabeça entre as bordas, entrando e saindo do aro em grandes saltos com agilidade maravilhosa" (MARKESSINIS, 1984, p. 46).

\section{Império Romano e Idade Média}

A ascensão do império Romano deu protagonismo à esta espetacularidade dos movimentos acrobáticos, presentes nas principais manifestações culturais e populares representantes do gigantismo do entretenimento da época, como a luta de gladiadores, a corrida de cavalos e o circo. Os acrobatas, em seus propósitos artísticos, festivos ou virtuosos, eram associados ao domínio de objetos (como equilibristas, malabaristas, funâmbulos ou pernas de pau), animais (saltos sobre eles ou domesticação) e entre outros para compor números de entretenimento que tomavam as ruas, porém, em sua maioria, eram de natureza teatral e não dançada.

A popularidade do movimento acrobático presente em manifestações públicas foi conduzida, a partir da Idade Média, a uma marginalização e consequente aspecto nômade. $\mathrm{O}$ poder da Igreja, a decadência das civilizações antigas, a simplicidade da vida e o desinteresse e falta de atenção às práticas físicas por parte da população foram responsáveis pela perda da importância das exibições acrobáticas. O catolicismo, em uma repressão que se estendia a toda atividade física e de arte corporal, proibia exercícios que tinham como finalidade a saúde do corpo (ULMANN, 1982, p. 85), e a habilidades dos herdeiros de equilibristas e 
funâmbulos por vezes provocam assombro frente à simplicidade da vida nas pequenas vilas (GARCÍA, 1979, p. 142).

O artista medieval, entretanto, caracteriza-se por ser polivalente. Os jeugleurs franceses possuíam as competências variadas de atuação, acrobacia, malabarista, dança, música, poesia e contação de histórias em suas apresentações públicas. No final do século $\mathrm{XIV}$, os grupos dos jeugleurs foram divididos em duas classes distintas: os jeugleurs e volteadores. Estes últimos dedicaram-se exclusivamente a exercícios de agilidade, à exibição de animais treinados, a números cômicos e à dança na corda (ROHE, op. cit., p.155). As antigas acrobacias da antiguidade clássica são mais uma vez exibidas no palácios ou nas praças das cidades para aqueles aventureiros que costumavam manter o ritmo criado por violinos ou flautas com mil cabriolas; eles faziam "a ponte" ou ritmicamente caminhavam nas mãos, para tornar-se uma dança em vez de uma exibição de habilidade de ginástica, muito próxima das habilidades de bufões e saltimbancos (BONILLA, 1964, p. 123).

A condenação dos movimentos acrobáticos, por parte da doutrinação cristã, fica evidente através da análise da representação iconográfica da figura bíblica da bailarina Salomé, apontada como a responsável da morte a exibição da cabeça de João Batista em uma bandeja de prata após uma dança realizada em um banquete festivo. Em várias ilustrações da época, se vê a jovem dançando em posições acrobáticas ou de cabeça para baixo sobre os dois braços (MARKESSINIS, op. cit., p. 19-20), colocando-a em equivalência com os populares jeugleurs, artistas que a Igreja perseguia como uma ameaça. A representação da maldade de Salomé através de uma dança acrobática era uma maneira de colocar uma conotação negativa sobre qualquer entretenimento envolvido com a dança ou o circo (NEGINSKY, 2013, p. 26); e o simbolismo da inversão é tomado não mais como uma associação ao divino, mas ao seu contrário.

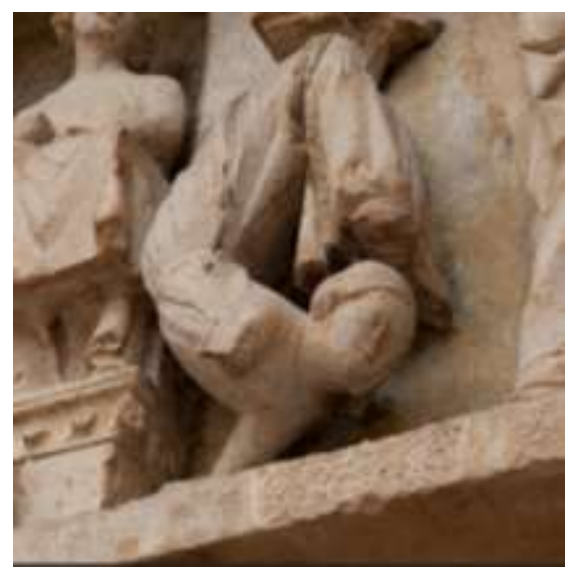

Figura 7 - Detalhe de uma escultura da Catedral de Rouen (França), representando a dança de Salomé. Fonte: https://www.flickr.com/photos/paulodykes/26521251883. Acessado em 20/12/2019. 
O jogo representativo de binômios entre corpos direito/invertido sugere as oposições fundamentais deus/diabo ou vida/morte (BROZAS, op. cit., p. 25). A permanência de uma função religiosa de acrobacia é confirmada na lenda francesa Le Tombeur Notre Dame, do século XIV, em que o monge malabarista dedica suas piruetas à Virgem (DUFRÊNE, 1997, p. 4). A história conta que

um acrobata, cansado de vagar pelo mundo, renega seu dinheiro, cavalo e roupas, e ingressa num mosteiro. Todas as noites, secretamente, ele desce à cripta, onde há uma estátua de Nossa Senhora na capela. Tira seu hábito, veste sua camisa fina e a venera , não com orações, mas com danças acrobáticas. Executa os saltos francês, espanhol e bretão, "rodopia seus pés no ar", caminha apoiado nas mãos - até que exausto, desmaia. O abade, advertido de seu estranho comportamento, o observa secretamente e testemunha um milagre: Maria desce do Céu e abana o acrobata prostrado. Profundamente comovido, o abade o toma nos braços e o admite na comunidade dos frades (...) A ópera de Massenet, Le Jongleur de Notre Dame (1902), é baseada nesta velha lenda. (BERTHOLD, 2001, p. 246-247).

\section{Renascimento e Barroco}

A partir do Renascimento, os artistas circenses voltaram a tomar as ruas e povos dos países europeus, buscando entreter e encantar o público, tirando os habitantes das rotinas duais de trabalho e descanso (SOARES, 2001, p. 33- 41). Apesar das apresentações artísticas predominarem nas praças e feiras, se desenvolveu na França diversas atividades de corte acrobáticas, integrando os acrobatas à corte. Era constante a aparição e apresentação de equilibristas em cerimônias de recepção, coroações e comemorações de reis, algumas nunca antes vistas, como dançarinos sobre a corda, que pendia amarrada desde as torres da igreja às do castelo, realizando verdadeiras pantomimas sobre ela (ROHE, op. cit., p. 162-163).

O movimento acrobático sobrevive timidamente nos ballets clássicos da corte desenvolvidos no reinado de Louis XIV, como o relato de um acrobata chamado Cordellin que dançava sobre a corda no ballet de armas da França (MENIL, op. cit., p. 336). Desta forma, apesar da relação de subordinação da acrobacia com a dança clássica, surge um processo de integração e absorção de técnicas acrobáticas, o que se conclui que a estrutura do ballet clássico incluía acrobacia (SILVA, 1999, p. 32-33).

Movimentos como o grand ecart, equilíbrio com o pé na mão, na cabeça ou mãos, a ponte, cambalhotas para frente e trás, o mortal para frente, a roda lateral e caminhar sobre as mãos eram utilizados para enriquecer o vocabulário coreográfico como para adotar à um personagem (GULLOT e PRUDHOMMEAU, 1974, p. 147-150). Algumas fontes contam que Luís XIV estreou em um espetáculo denominado "La Prosperitée" em 1641 executando um flic-flac no solo (BROZAS, op. cit., p. 31). 


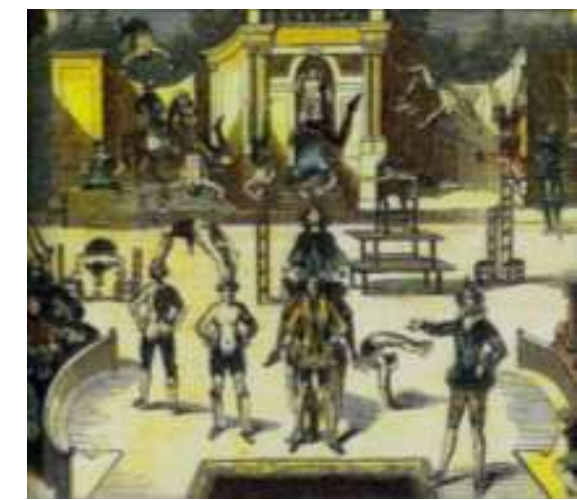

Figura 8 - Teatro dos grandes bailarinos do rei, contendo diversos movimentos acrobáticos. Fonte: Jacob, P., op. cit., p. 35.

Os movimentos acrobáticos contribuem na construção de uma hegemonia vertical do ballet clássico francês e no desenvolvimento da dança, ao permitir à bailarina permanecer ficar mais tempo em ponta ou no ar e realizar um número maior de piruetas (ibidem, p. 196199). Entretanto, estes movimentos “especificamente acrobáticos pelo nível de altura que a bailarina alcança" (SERRES, 2002, p. 20), como o adage pás de deux, não são passíveis de serem feitos sozinhos, sendo necessário a presença de um parceiro, em um jogo semelhante às acrobacias em dupla.

Com a propagação do humanismo prático e do culto ao corpo a partir do século XVI, a presença de acrobacias nas cortes promove o desenvolvimento dos primeiros tratados sobre metodologia ginástica, o nascimento e evolução do circo moderno e a criação de escolas. Desta forma, o movimento acrobático entrou em um processo de institucionalização, e esportivização. As trocas socioculturais e a transformação da sociedade cada vez mais têm criado novos conceitos acrobáticos em práticas como a Ginástica (em suas diversas modalidades, como a artística, rítmica, de trampolim, aeróbica, acrobática), Cheerleading, patins, bicicleta, skate, patinetes, snowboarding, skiing, slackline, parkour, bungee jumping, saltos ornamentais, patinação no gelo, ioga, judô, karatê, taekwondo, aikido, kung fu. Porém, em culturas dançadas, a acrobacia se presencia no music-hall, nos bailes de salão, no rock'n'roll acrobático, no teatro musical, na dança-teatro, no contato-improvisação, na dança vertical, nas danças folclóricas, no hip-hop e na capoeira.

\section{Music Hall}

A partir da segunda metade do século XIX, a Belle Époque transformou movimentos acrobáticos em símbolos obscenos e erotizados, que, em conjunto de um ritmo frenético, tornou-se uma dança muito popular em cabarés, cafés, concertos e music halls, do Follies- 
Bergère ao Moulin Rouge. Um grupo de mulheres, vestindo roupas coloridas e esvoaçantes, dançam ao som de trombones e cornetas um ritmo energético. Passos compostos por movimentos acrobáticos de contrapeso e de flexibilidade representam os extremos da sensualidade, através de lançamentos de pernas, giros no eixo ou passagens pelas costas de parceiros (ROHE, op. cit., p. 222-224). Destacam-se como artistas deste gênero Mistinguett, Loïe Fuller, las Hoffman Girls, Los Atena, los Frediani, entre outros.

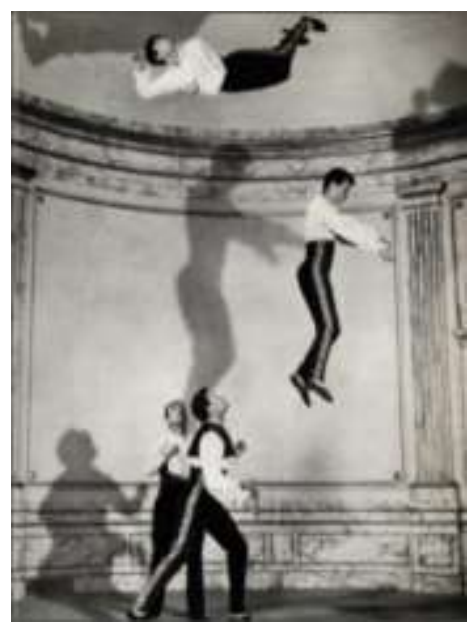

Figura 9 - Los Frediani, Empire (1957). Fonte: DAMASE, 1960, p. 169.

\section{Teatro Musical}

O Teatro Musical é um gênero teatral ou cinematográfico em que a ação se desenvolve através de cenas cantadas e danças, sendo os maiores representantes as apresentações do West End, em Londres, e a Broadway, em Nova York. Derivada das operetas, óperas cômicas e do music hall, o teatro musical combina música, teatro, dança e acrobacia a serviço do desenrolar dramatúrgico. A acrobacia é integrada como movimento nas coreografias, realizada pelos coros e protagonistas, convertendo-se em um código expressivo e possibilitando uma maior espetacularidade da obra. Em muitas companhias, a acrobacia é utilizada como disciplina fundamental de treinamento, e há geralmente o posto de acrobata (ibidem, p. 205-206). Na produção da Broadway de "O Homem-aranha", por exemplo, as capacidades acrobáticas permitem a semelhança com habilidades aracnídeas que fazem parte da narrativa. 


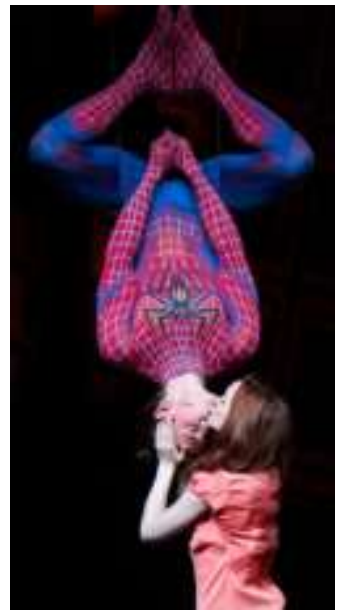

Figura 10 - Acrobacia aérea em “O Homem-aranha”. Fonte: http://es.globedia.com/spider-man-musical-york. Acessado em 21/12/2019.

\section{Dança-teatro}

Na Dança-teatro ou na Dança Contemporânea, os movimentos acrobáticos podem assumir códigos expressivos por si mesmos ou são revelados através de técnicas de contato improvisação, capturas e equilíbrios dinâmicos invertidos (ibidem, p. 231). O coreógrafo Wim Vandekeybus, no espetáculo What the body does not remember (1987), com sua companhia Ultima vez, inicia sua exploração com a dança de risco. Os jogos acrobáticos são marcados pela dureza das ações, a intensificação da energia, a interação violenta do intérprete com a música e cenário, sem negligenciar a reflexão e o humor. Os atores-bailarinos realizam deslocamentos, saltos, quedas, lançamentos, recepções e balanços sobre uma corda atada aos pescoços de outros bailarinos. Em Inmer das Selbe Gelogen, um dos intérpretes mantinha-se sentado em uma cadeira disposta inversamente durante vários minutos (ibidem, p. 232-233).

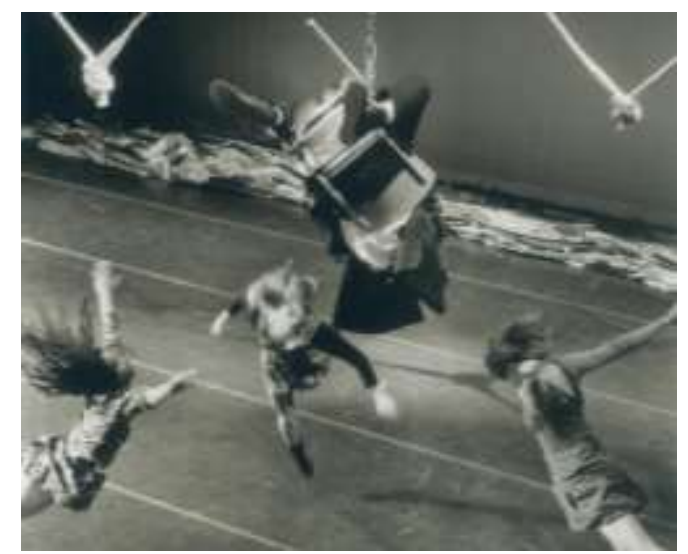

Figura 11 - Inmer das Selbe Gelogen (1991), do grupo Ultima Vez. Fonte:

https://www.ultimavez.com/en/productions/immer-das-selbe-gelogen. Acessado em 21/12/19.

O diretor Jan Fabre já dirigiu mais de 30 produções que combinam teatro e dança. Leva à cena seus interesses plásticos, entrelaçando-os com a preocupação pelos conflitos, 
sendo a relação ordem/caos uma de suas obsessões. Em seu espetáculo The Power of Theatrical Madness, a experiência da complexidade envolve o uso da violência, uma violência que começa por conta própria e é projetada nas bailarinas: as mulheres cujos corpos foram treinados na disciplina do balé clássico são submetidas por Fabre a uma nova disciplina, que tem mais a ver com imobilidade, rigidez, repetição mecânica. Em Angel of Death um de seus atores atravessa o palco em diagonal andando sobre as mãos (ibidem, p. 233-234).

\title{
12. Contato-improvisação
}

O Contato-improvisação é uma técnica de dança no qual os pontos de contato físico são o ponto de partida para a exploração do movimento em relação com o outro, através da improvisação da troca de peso, toque e movimento. Inaugurada através da performance Magnesium, de Steve Paxton e bailarinos da Oberlin College, é

\begin{abstract}
uma dança de contato com técnicas predominantemente acrobáticas cujo processo coreográfico se embasa completamente na improvisação coletiva. É uma forma de dança cujos conteúdos técnicas se abastecem da acrobacia (...) Toda acrobacia está baseada em uma transgressão postural e/ou motriz que se caracteriza por uma relação inabitual com a gravidade. No Contato-improvisação, entretanto, se produz uma transgressão das distâncias corporais a partir do contato permanente e se acentua a experiência do espaço circular (...) a chave se situa no processo de comunicação, na capacidade de escuta assim como de reação e iniciativa, o intérprete deve inventar o movimento a partir daquilo que seu parceiro vai inventando simultaneamente. (BROZA, 2000).
\end{abstract}

Pode ser vista por uma tríade de perspectiva coreográfica, pedagógica e acrobática. Esta é percebida em elementos técnicos como apoios, quedas, giros, inversões; como em bases perceptivas como equilíbrio, tato e visão periférica. As exigências perceptuais da atividade acrobática - constante adaptação sensorial à giros e inversões - são acentuadas na medida em que há uma total falta de previsão em relação ao movimento a ser feito. Assim, o Contato Improvisação difere de outras atividades acrobáticas de contato, onde a orientação é constantemente desafiada de forma visual, direcional, de equilíbrio e concernente ao lugar de consciência no corpo. Desta forma, busca-se por uma abordagem através do relaxamento como um estado que ajuda a aquisição da plena consciência e o funcionamento perceptual, pois a tensão tende a mascarar a sensação (idem). 


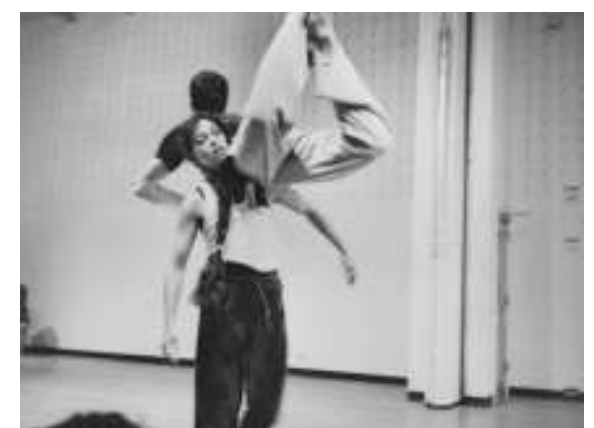

Figura 12 - Nancy Stark Smith e Steve Paxton (1984). Fonte: http://nancystarksmith.com/biography/. Acessado em 21/12/19.

\section{Dança vertical}

A Dança Vertical é uma modalidade de dança contemporânea que está ganhando cada vez mais adeptos e espaços devido a sua espetacularidade e integração com as linguagens circenses e acrobáticas. O trabalho aéreo, realizado com coreografias em tecidos aéreos circenses em teatros tradicionais, com cabos de segurança em paredes verticais e fachadas de prédios, ou presente na dança bungee, em que os dançarinos ficam suspensos por cordas elásticas. Esta última é popular entre academias com objetivos desportivos e aeróbicos por diminuir o impacto, tornando as coreografias mais leves e lúdicas.

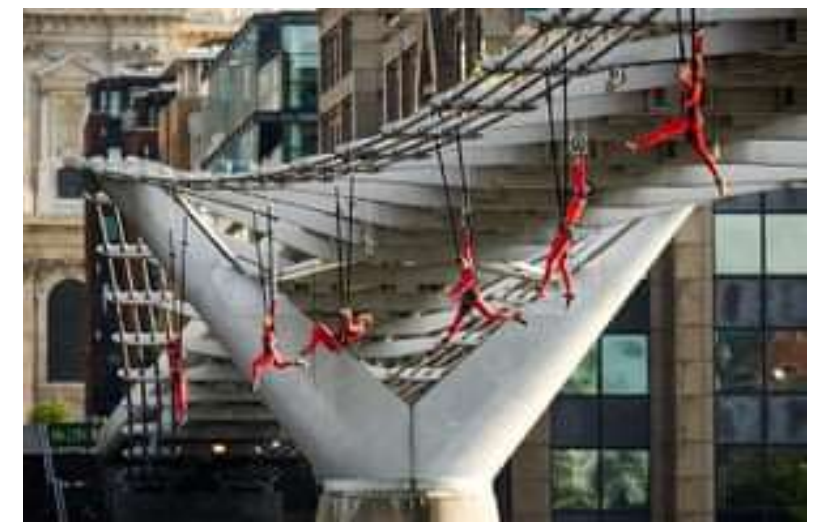

Figura 13 - Performance Waterfalls (2012), da coreógrafa estadunidense Elizabeth Streb. Fonte: https://www.theguardian.com/stage/gallery/2012/jul/15/elizabeth-streb-london-dancepictures. Acessado em 21/12/19.

\section{Bailes de salão/Rock'n'roll acrobático}

Os bailes de salão surgiram a partir da evolução sonora de estilos musicais como o swing, o boogie woogie e, principalmente, com o rock'n'roll, abreviação da expressão inglesa que significa "balançar e virar". Os bailes de salão contaram com um processo de esportivização, contando com campeonatos em diferentes modalidades, e as acrobacias estão mais presentes no rock'n'roll acrobático (ROHE, op. cit., p. 236). Os movimentos acrobáticos 
são componentes de coreografia e sua espetacularidade pode ser comparada a das acrobacias em duplas e o contato-improvisação:

a relação e os papéis coincidem com os de volante e portô da ginástica acrobática. $\mathrm{O}$ portô deve ter a responsabilidade de oferecer o máximo de segurança ao volante. O domínio do equilíbrio dinâmico se associa à colocação do centro de gravidade no polígono de sustentação, mediante a utilização das pernas, retroversão do quadril, etc. $\mathrm{O}$ volante deve iniciar os desiquilíbrios a partir dos pontos de apoio do portô que vão permitir realizar figuras aéreas, manuais, invertidas, etc. (RIZO e TONNERLIER, 1993, p. 51-56)

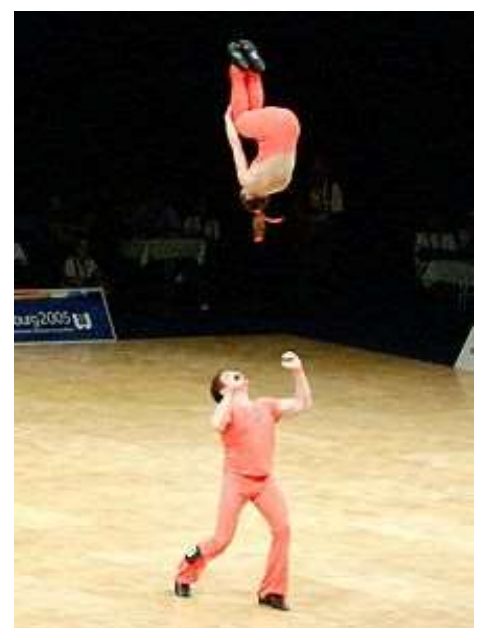

Figura 14 - Daniela Bechtold and Bernd Diel (2005), em um número de Rock'n'roll acrobático. Fonte: https://es.wikipedia.org/wiki/Rock_and_roll_(baile). Acessado em 22/12/19.

\section{Danças Folclóricas}

Em algumas danças folclóricas em distintas regiões espanholas se descreve uma ação acrobática que culminava e coincidia com uma coreografia composta por pirâmides humanas; corpos que subiam acima um dos outros em uma composição estática ou dinâmica. A acrobacia representa a união entre os participantes e eleva a superação dos limites ao máximo. Atualmente, na Catalunha, há a presença dos Castellers de Vilafranca, uma instituição cultural e desportiva que tem como objetivo construir torres humanas; e Muixeranga, na comunidade valenciana. 


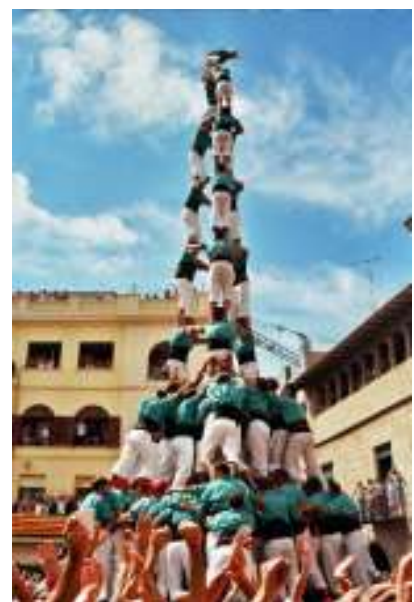

Figura 15 - Castellers de Vilafranca. Fonte: https://en.wikipedia.org/wiki/Castellers_de_Vilafranca. Acessado em 22/12/19.

\section{Hip-hop}

$\mathrm{O}$ estilo de dança break dance, chamado também de street dance, dança urbana ou hip-hop nasce nos anos 70, em Nova York. Seus praticantes, em sua maioria, têm formação autodidata, através do qual integram técnicas de movimento baseadas no erro e imitação direta dos companheiros. A dança é realizada majoritariamente dentro das rodas de exibição que o grupo forma na rua, ao mesmo tempo em que reivindica seus direitos sociais através dos espaços urbanos (ROHE, op. cit, p. 237).

O head spin ou giro sobre a cabeça, é um exemplo do uso acrobático do movimento e se converteu como principal símbolo técnico da dança: a inversão das hierarquias sociais e o movimento concêntrico ao redor dos break dancers (RIZZO e VEIGA, 1998, p. 28-29). Com o passar do tempo, o hip-hop sofreu negativamente com o processo de esportivização, que, apesar de desenvolver o nível técnico e competitivo das batalhas, houve uma perda considerável de seu caráter artístico original, sendo deixada a improvisação como base do processo de criação artística (BROZAS, op. cit., p. 119).

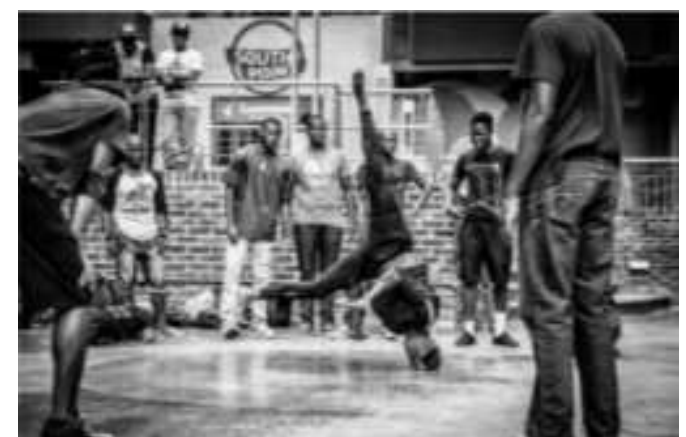

Figura 16 - Head spin em São Petersburgo, África do Sul. Fonte: https://www.pixoto.com/images-photography/city-street-and-park-/street-scenes/headspin-6216548669718528. Acessado em 22/12/19. 


\section{Capoeira}

A Capoeira é uma manifestação cultural brasileira que integra dança, artes marciais, acrobacia, música, filosofia, espiritualidade, esporte, cultura popular e jogo. Com origem nos Quilombos entre os estados de Alagoas e Pernambuco, pelos primeiros escravizados africanos trazidos ao Brasil, primeiro como dança e depois se transformou em uma luta acrobática, possivelmente sobre a influência de rituais africanos já existentes, como a N'Golo ou "a dança das zebras" (ROHE, op. cit., p. 238-239). A denominação é de origem indígena tupi-guarani, e significa "mato que foi", em referência às vegetações rasteiras que os escravos utilizavam para fugir ou esconder, praticando as lutas com centro de gravidade muito baixo (FERREIRA, 1986, p. 334).

A Capoeira foi proibida durante o período colonial, porém a prática foi continuada nas rodas de batucadas à noite após o dia de trabalho forçado, como uma esperança de sobrevivência e liberdade. Com a instauração da República, o então presidente M. Deodoro da Fonseca decretou, no decreto $\mathrm{n}^{\circ} 847$ de 1890, como proibido "fazer nas ruas e praças públicas exercícios de agilidade e destreza corporal conhecidos pela denominação capoeiragem". Somente em 1932, com o mestre Bimba, que colocou a prática nos ginásios e atinge a classe média e burguesa, que se inicia a desmarginalização da prática (SODRÉ, 2002). Os golpes, transmitidos oralmente por um mestre, são movimentos ágeis e complexos, se dão por meio de acrobacias em solo ou aéreas. Sua atualidade se manifesta na preservação da cultura afrobrasileira, como ferramenta de educação, socialização e atividade física.

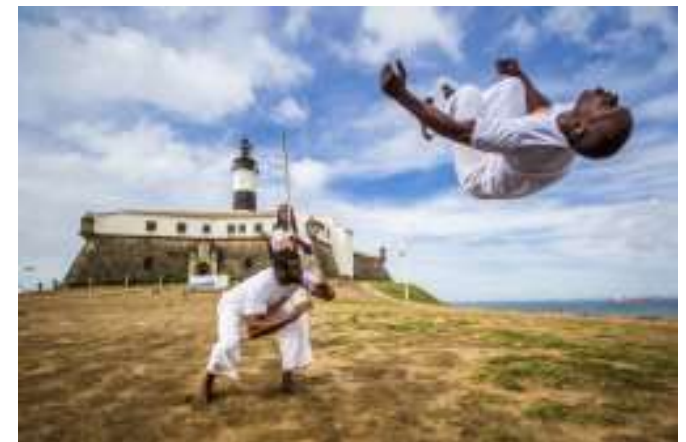

Figura 17 - Salto na Capoeira. Fonte: https://sportlife.com.br/capoeira-beneficios-esporte-2/. Acessado em 22/12/19.

\section{Conclusão}

O movimento acrobático, presente nas manifestações culturais dançadas, assemelhamse em grande parte com acrobacias bem delineadas que compõem o universo do esporte, porém apresentam certas variações em sua execução. A popular “estrelinha” da Ginástica 
Artística é perfeitamente realizada por ginastas de acordo com leis gímnicas de alinhamento, ritmo constante e beleza estética, por exemplo. Porém, na capoeira, este movimento similar não é regido por princípios biomecânicos esportivos, e sim com o objetivo de uma mobilidade feita através da transferência do peso do corpo para os braços, que ocasiona em uma inversão acrobática.

Desta forma, a importância do movimento acrobático para as manifestações culturais não é a perfeição, virtuosismo ou eficácia da sua execução, mas é regida por outros princípios, sejam eles sociais, rituais, religiosos, festivos, espetaculares, técnicos, expressivos, pedagógicos, lúdicos, coreográficos ou de treinamento. Entretanto, em termos comuns, a acrobacia, nas práticas culturais apresentadas neste artigo, sempre esteve um caráter cênico: um movimento que, ao colocar o homem em um contexto imaginário por meio de rupturas perceptivas e corporais que desafiam as leis gravitacionais conjuntamente com uma expansão de qualidades físicas e motoras, é executada diante de um público.

\section{Referências}

AQUESOLO, J. A. Diccionario de las ciências del deporte. Málaga, Unisport, 1992.

BARBA, E. A arte secreta do ator - um dicionário de Antropologia Teatral. São Paulo: É Realizações, 2012.

BARBA, E. Le canöe de papier: Traité d'Anthropologie Théâtrale. Bouffonneries no 28-29, Lectoure, Bouffonneries, 1993.

BERTHOLD, Margot. História mundial do Teatro. Perspectiva, 2001.

BONILLA, Luis. La danza en el mito y en la historia. Vol I, Madrid: Biblioteca Nueva, 1964. BROZA, M. Em torno a la definición del Contact Improvisation desde uma perspectiva: coreográfica, acrobática y pedagógica. Revista Efdeportes, $\mathrm{n}^{\circ}$ 22. Buenos Aires, 2000. Disponível em: < http://www.efdeportes.com/efd22a/ci.htm>.

BROZAS, M. P. Fundamentos de las actividades gimnásticas y acrobáticas. León, Universidad de León, 2004.

CHEVAlIER, J.; GHEERBRANT, A. Diccionario de los símbolos. París, Ed. Robert Laffont et Ed. Jupiter, Barcelona, Libergraf, S. L, 1995.

DUFRÊNE, Thierry. Acrobate mime parfait, l'artiste en figure libre. Museos de la Ville de Paris, 1997.

FERREIRA, A.B.H. Novo Dicionário Aurélio. Rio de Janeiro: Nova Fronteira, 1986.

GARCÍA, V. El circo - enciclopedia del mayor espectáculo del mundo. Madrid, Nova, 1979. 
GULLOT, Genevieve; PRUDHOMMEAU, Germaine. Gramática de la Danza clásica. Hachette, Buenos Aires, 1974.

HOMERO. Odisseia. São Paulo: Cosac Naify, 2014.

DEONNA, W. Le simbolisme de l'acrobatie antique. Latomus: Bruxelas, 1953.

DEPPING, G. Merveilles de la forcé et de l'adresse. Paris: Hachette, 1871.

LEXOVÁ, I. Ancient Egyptian Dances. Dover P. Inc, Mineola, N.Y, 2000.

MANDELL, R. D. Historia Cultural del Deporte. Barcelona, Ed. Bellaterra, 1986.

MARKESSINIS, A. Historia de la danza desde sus Orígenes. Madrid: L. D. Esteban Sanz, 1984.

MAUSS, M. As Técnicas Corporais. In: Sociologia e Antropologia. São Paulo, EPU, 1974.

MENIL, F. Histoire de la danse a travers les ages. Paris: Alcide Picard \& Kaan Ed, 1905.

NEGINSKY, Rosina. Salome: the image of a woman who never was. Cambridge: Cambrige Scholars Publishing, 2013.

PEIGNIST, M. Histoire anthropologique des danses acrobatiques. Corps, nº 7, 2009.

PRADIER, Jean-Marie. Etnocenologia. In: BIÃO, A; GREINER, C. Etnocenologia: textos selecionados. São Paulo: Annablume, 1999.

PUTRI, Saraswati. The revival of Sang Hyang Dedari dance: a phenomenological approach to social-ecological reconstruction in Bali. In: ASEAN Journal of Community Engagement, Volume 1, Number 1, 2017, p. 72-82.

QIFENG, Fu. Chinese Acrobatics Through The Ages. Foreing Languages Press: Beijin, 1985. RIZO, J.; TONNELIER, H. Rock'n'roll acrobatique. Revue E.P.S, nº 243, 1993.

RIZZO, F.; VEIGA, L. Breakdance. Tiempo de danza nº 17, pp. 28-29, 1998.

ROHE, J. La acrobacia dramática en la formación y el entrenamiento actoral. Tesis doctoral, Universidad de Málaga. Málaga, 2014.

ROHE, J. I. A. T. Evolución histórica de las danzas acrobáticas. Revista Danzaratte, Año X, $\mathrm{n}^{\circ} 9,2015$.

SERES, G. Le pas de Deux. Les portés. Manuel d'aprentissage. Paris. Désiris, 2002

SILVA, L. Los Buenos viejos tiempos. Tiempo de Danza nº 20, Buenos Aires, 1999.

SOARES, C. Acrobacias e Acrobatas: Anotações para um estudo do corpo. Campinas, Ed. Autores Associados, 2001.

SODRÉ, M. Mestre Bimba: corpo de mandinga. Manati, 2002

STREHLY, Georges. L'acrobatie et les acrobats. Paris: Zlatin, 1977.

ULMANN, J. De la gymnastique aux sports modernes. Histoire des doctrines de l'education physique. Vrin, Paris, 1982. 